\title{
Fourier transform infrared spectroscopy-chemometric approach as a non-destructive olive cultivar tool for discriminating Portuguese monovarietal olive oils
}

\author{
Sandra Lamas $^{1} \cdot$ Nuno Rodrigues $^{1} \cdot$ Isabel P. Fernandes ${ }^{1} \cdot$ Maria F. Barreiro $^{1} \cdot$ José A. Pereira $^{1} \cdot$ António M. Peres ${ }^{1}$ (i)
}

Received: 29 April 2021 / Revised: 8 June 2021 / Accepted: 27 June 2021 / Published online: 7 July 2021

(c) The Author(s), under exclusive licence to Springer-Verlag GmbH Germany, part of Springer Nature 2021

\begin{abstract}
Four Portuguese monovarietal olive oils (cvs. Cobrançosa, Madural, Santulhana and Verdeal Transmontana) were evaluated, totalizing 24 independent samples. Olive cultivar significantly influenced ( $P$ values $<0.05$, one-way ANOVA) the oils' physicochemical and sensory attributes, fulfilling all oils the legal thresholds for extra-virgin classification. Oils from cv. Verdeal Transmontana had the highest oxidative stability $(16.9 \pm 1.0 \mathrm{~h})$, whereas cvs. Cobrançosa and Santulhana oils have the highest total phenols content ( $204 \pm 30$ and $177 \pm 33 \mathrm{mg} \mathrm{GAE} / \mathrm{kg}$, respectively). Concerning the sensory attributes, only cv. Santulhana oils fitted fruity greenly oils type, presenting, in general, significantly higher olfactory and gustatory intensities ( $P$ values $<0.05$, one-way ANOVA), with a higher number of perceived sensory attributes (e.g., herbaceous sensations), compared to the other monovarietal oils. Free acidity, peroxide value, extinction coefficients, total phenols and oxidative stability allowed the unsupervised differentiation (principal component analysis, PCA) of the four monovarietal oils, and in a less extent, the sensory data. Fourier transform infrared (FTIR) spectroscopy-chemometric procedure was developed based on raw or transformed forms of the recorded spectra. Raw, 1st and 2nd derivative spectra allowed the unsupervised (PCA) and supervised (linear discriminant analysis, LDA) identification of the olive cultivar of the studied oils. In fact, FTIRLDA models, based on the raw transmittance or on their 1st or 2 nd derivatives, recorded at 5,4 or 3 selected wavenumbers, respectively, allowed to correctly classify all oils (sensitivities greater than $99 \pm 7 \%$ for the repeated K-fold-CV internal validation). Therefore, FTIR spectroscopy could be used as a fast, reliable, environmentally friendly and non-destructive olive cultivar-classification tool for monovarietal oils.
\end{abstract}

Keywords Olive oil · Fourier transform infrared spectroscopy · Data processing · Portuguese cultivar discrimination · Authenticity

\section{Introduction}

Olive oil is widely used in the Mediterranean diet, being its consumption associated with several health benefits [1]. This vegetable oil is one of the most valued in the world, being commercialized as extra virgin or virgin olive oil (EVOO or $\mathrm{VOO}$, respectively), which include both blend and monovarietal olive oils. The latter ones are usually appreciated by consumers and commercialized at higher prices, and thus,

António M. Peres

peres@ipb.pt

Centro de Investigação de Montanha (CIMO), Instituto Politécnico de Bragança, Campus Santa Apolónia, 5300-253 Bragança, Portugal more prone to deliberated adulterations. Several analytical techniques, including physicochemical, sensory, electrochemical, metabolic, and genomic based-strategies in combination with chemometrics, have been proposed, aiming to ensure the authenticity of monovarietal EVOO, guaranteeing the labeling correctness regarding the olive cultivar [2-6]. Although these analytical strategies can be used to accurately assess the cultivar/botanical origin of monovarietal olive oils, most of them rely on a destructive analysis, being needed to pretreat the oils' samples, requiring in some cases the combination of several analytical techniques, turning out into a time-consuming and expensive process [7].

Spectroscopy-based tools can be a feasible alternative, allowing a fast and non-destructive/non-invasive analysis of olive oils [7-9]. Among these, Fourier transform infrared (FTIR) spectroscopy has emerged as a key tool for the 
traceability and authenticity of foods [10]. In fact, FTIR spectroscopy has been widely applied for olive oils analysis since edible vegetable oils' spectrum $\left(4000-600 \mathrm{~cm}^{-1}\right.$ zone) contains well-resolved intense bands that correspond to the fundamental vibrations of specific functional groups of the main oil constituents [11]. To extract the valuable information gathered with the infrared absorption spectra, qualitative (e.g., principal component analysis, PCA; cluster analysis, CA; linear discriminant analysis, LDA; and soft independent modeling of class analogy, SIMCA) and quantitative (e.g., principal component regression, PCR; partial least square regression, PLSR; multiple linear regression models, MLRM; and artificial neural networks, ANN) chemometric tools coupled with different variable selection algorithms (e.g., successive projections algorithm, SPA; uninformative variable elimination, UVE; simulated annealing, SA; and genetic algorithms, GAs) are commonly employed [11].

FTIR-chemometric tools allowed the quantification of several characteristics of olive oils (e.g., fatty acids, wax, diacylglycerol, squalene, iodine values, free acidity, peroxide value, color pigment contents, sensory intensities and rancid markers, phenol content and antioxidant activity, among others) [12-19], the identification of olive oil adulteration/mixing with different vegetable oils as well as to discriminate olive oils from other vegetable oils [14, 20-26], to discriminate the geographical origin of olive oils $[12,27,28]$, to evaluate the thermo/auto oxidation of olive oils $[29,30]$, and to differentiate/classify olive oils according to their commercial grade [31]. Besides these applications, olive oils were also successfully classified according to the olive cultivar/botanical variety, which constitute a major commercial interest due to the high value of monovarietal oils. In this sense, Turkish olive oils were correctly classified according to the cultivar (cvs. Ayvalik, Erkence, Gemlik, Memecik and/or Nizip) based on FTIR-PCA approaches [27, 32, 33]. Similarly, monovarietal Spanish olive oils were also correctly classified (sensitivity of $88 \%$ ) according to the olive cultivar (cvs. Arbequina, Borriolenca, Canetera, Farga, Hojiblanca, Picual, or Serrana) using a FTIR-LDA approach [34]. Gouvinhas et al. [35] showed that FTIR spectra coupled with PCA or LDA allowed classifying, simultaneously, the maturation stage and the olive cultivar (two Portuguese and one Spanish) of three monovarietal oils (cvs. Cobrançosa, Galega and Picual), providing correct classifications in the range $74-88 \%$, depending on the ripening stage. More recently, the same research group showed that this latter methodology could even allow the clonal assessment (i.e., phenotypes' selection) of cv. Cobrançosa oils, with a successful classification rate of $94 \%$ [36]. Cultivar discrimination (100\% of correct classifications) of Tunisian extra-virgin olive oils (cvs. Chemchali, Chemlali, Dhokar, Fouji, Jemri, Zalmati and Zarrazi) based on FTIR-LDA was also reported by Abdallah et al. [37]. Lastly, Revelou et al. [38] verified that FTIR spectroscopy combined with linear or quadratic discriminant analysis enables the correct discrimination (96\%) of the botanical origin of three commercial Greek monovarietal olive oils (cvs. Koroneiki, Megaritiki and Amfissis).

In this context, four monovarietal Portuguese olive oils were studied. The olive cultivars were selected due to the high economic importance in terms of production and/or valorization of the extracted olive oils. Cobrançosa is a very spread olive cultivar; Madural, Santulhana and Verdeal Transmontana were included due to the highly appreciated sensory characteristics of the respective olives and monovarietal olive oils [39]. All olive oils were evaluated taking into account the physicochemical quality parameters (free acidity, FA; peroxide value, PV; and extinction coefficients, $K_{232}$ and $K_{268}$ ), total phenols content (TPC), oxidative stability (OS) and sensory profile (olfactory and gustatory attributes) aiming to classify them according to the correct olive cultivar (cvs. Cobrançosa, Madural, Santulhana and Verdeal Transmontana) based on an unsupervised multivariate approach (i.e., PCA). FTIR spectroscopy combined with PCA was also implemented to evaluate if this nondestructive analytical tool could be used as an alternative tool for cultivar discrimination. Finally, a FTIR-LDA-SA methodology was further used to identify the most discriminant infrared absorption wavenumber region(s).

\section{Materials and methods}

\section{Samples}

Four monovarietal Portuguese olive oils, from cvs. Cobrançosa, Madural, Santulhana and Verdeal Transmontana, were obtained from different olive oil producers located in the region of Trás-os-Montes, northeast of Portugal. Olives were grown under the same agro-climatic conditions and collected at similar maturation index (MI greater than 3.5, which corresponds to a fruit with black epidermis and with a white to reddish pulp), aiming to restrict the known influences of the olive ripeness level and geographical origin on the oils composition and thus, to highlight the olive cultivar effect. Olives were harvested during the last week of November and the first week of December 2020. The olive oils were industrially extracted under similar conditions (time and temperature of malaxation) using two-phase olive mills and following the good practices of olive oils extraction. The correctness of the olive cultivar used to produce the monovarietal olive oils was guaranteed by the technicians of the Integrated Production Growers Association (APPITAD, Portugal). For each cultivar, six independent glass amber bottles were collected. Each bottle, of $500 \mathrm{~mL}$ of oil, was 
filled during the extraction of olives from independent olive batches. The samples were coded and stored at room temperature and protected from light exposure until analysis, which was performed after 2 months of the oils' extraction.

\section{Olive oil physicochemical analysis}

Free acidity (FA, in \% oleic acid), peroxide value (PV, in $\mathrm{mEq} \mathrm{O}_{2} / \mathrm{kg}$ ) and specific coefficients of extinction at $232 \mathrm{~nm}$ and $268 \mathrm{~nm}\left(K_{232}\right.$, and $\left.K_{268}\right)$ were evaluated according to the European Union Regulation [40]. Oxidative stability (OS, in $\mathrm{h}$ ) was determined under accelerated oxidation conditions $\left(120{ }^{\circ} \mathrm{C}\right.$ ) using the Rancimat method (Rancimat 743 , Metrohm CH, Switzerland), as previously described [41]. Total phenolic contents (TPC) were assessed following the methodology proposed by Capannesi et al. [42] with some modifications, as previously described [43]. Quantification (in $\mathrm{mg}$ of Gallic acid equivalents (GAE) per kg of oil) was carried out using external standard calibration in methanolic solution $80 \%\left(R^{2} \geq 0.9999\right)$.

\section{Olive oil sensory analysis}

The olfactory and gustatory sensations of the olive oils were assessed by a trained sensory panel following the methodologies described by the European Union standard methods [40]. The analysis was performed by 8 trained panelists of the olive oil sensory panel of the School of Agriculture of the Polytechnic Institute of Bragança (Portugal) [39]. The intensity of the perceived sensations was scored according to an unstructured continuous intensity scale ranging from 0 (no sensory sensation perceived) to 10 (maximum intensity of the sensory sensation perceived). The descriptive profile was assessed using a test sheet, with some modifications, as recommended by the International Olive Council [44] and as previously reported by Rodrigues et al. [39].

\section{ATR-FTIR spectroscopy: apparatus and olive oil analysis}

FTIR analysis was carried out using a MB300 FTIR from ABB (Zurich, Switzerland) operating in attenuated total reflectance (ATR) mode using a horizontal cell equipped with a diamond crystal. The spectra acquisition was done using $32 \mathrm{scans} / \mathrm{min}$ at a resolution of $4 \mathrm{~cm}^{-1}$, being the reading range between 4000 and $500 \mathrm{~cm}^{-1}$. Spectra were acquired and treated using the software Horizon MB version 3.4. The background was acquired every two consecutive assays. For each monovarietal olive oil, the spectra were acquired in duplicate for two sub-samples collected from each of the six oil independent samples (bottles). Finally, for statistical analysis, raw and transformed forms (1st and 2 nd derivatives) of the FTIR spectra of the monovarietal olive oils were used [19].

\section{Statistical analysis}

The four monovarietal olive oils' composition was analyzed using the one-way ANOVA followed by Tukey's post hoc multi-comparison test. Prior to the multivariate analysis, the weight of each variable was normalized by applying variable scaling and centering procedures. Principal component analysis (PCA) was applied as an unsupervised multivariate classification technique for evaluating the possibility of identifying the olive cultivar using the physicochemical data or the sensory profiles. In addition, PCA was performed on the raw FTIR spectra and their transformed forms (i.e., 1st and 2nd derivatives) to infer which spectrum pretreatment(s) would allow a better differentiation of the studied monovarietal oils according to the olive cultivar. For PCA, mean values of the replicates made for each analysis were used. Thus, for each evaluated parameter, the dataset totalized 24 values, corresponding to 4 monovarietal oils $\times 6$ independent bottles. The results are discussed based on the $2 \mathrm{D}$ or $3 \mathrm{D}$ plots of the first two or three principal components (PC) functions, respectively. Linear discriminant analysis (LDA) was applied to assess the studied oils' correct discrimination based on the FTIR data. The best subsets of wavenumbers (and related band intensities) were identified using the metaheuristic simulated annealing (SA) variable selection algorithm. The SA is a probabilistic technique that aims a global optimization, being based on the physical annealing process of solids $[45,46]$. In this sense, and oppositely to deterministic optimization techniques, the SA algorithm deals with non-optimal solutions during the optimization, is capable to cross along local optimums and to identify the global optimal solution [46, 47]. The SA algorithm is a robust variable selection algorithm that has been previously applied within the spectroscopy field allowing enhancing the robustness of the developed models in which concerns model transfer and predictive capability $[46,48,49]$. For the selected LDA models, the variables normality distribution was checked using the Kolmogorov-Smirnov normality test with the Lilliefors significance correction. The homogeneity/equality of the variance-covariance matrices was assessed using the Box's $M$ test, and the multicollinearity was evaluated based on the correlation matrix. However, it should be noticed that LDA is fairly robust to a moderate violation of these assumptions [50, 51]. In which concerns the internal validation, both the leave-one-out cross-validation (LOO-CV) and the repeated $\mathrm{K}$-fold-CV variants were considered, being the latter implemented with 4 folds $(K=4)$ and 10 repeats (number of internal validations: 4 folds' 10 repeats $=40$ validation runs, allowing that at each time, $25 \%$ of the dataset was randomly selected for validation purposes, being the remaining 
$75 \%$ of the data used for training purposes). To avoid the risk that replicates from the same independent olive oil sample (bottle) of each studied monovarietal oil could be simultaneously included in the training and internal validation sets, mean values were also used. The predictive performance was assessed for both variants based on the established classification model's sensitivity and specificity. In addition, 2D plots of the two main discriminant functions (DF) were used, being the class membership ellipses established using the posterior probabilities, computed using the Bayes' theorem [52]. All data processing and statistical analyses (5\% significance level) were performed on the open-source statistical program R (version 3.6.2) and related software packages.

\section{Results and discussion}

\section{Physicochemical, TPC, OS and sensory profile of cvs. Cobrançosa, Madural, Santulhana and Verdeal Transmontana monovarietal olive oils}

The physicochemical quality data (FA, PV, $K_{232}$ and $K_{268}$ ), the OS and TPC of the four monovarietal Portuguese olive oils (cvs. Cobrançosa, Madural, Santulhana and Verdeal Transmontana) are shown in Table 1 . The sensory profiles and the intensities of the perceived olfactory and gustatory attributes are listed in Table 2 . It can be inferred that all studied monovarietal oils fulfilled the legal thresholds for being classified as EVOO (FA $\leq 0.8 \mathrm{~g}$ oleic acid/100 g, $\mathrm{PV} \leq 20 \mathrm{mEq} \mathrm{O} \mathrm{O}_{2} / \mathrm{kg}, K_{232} \leq 2.50$ and $K_{268} \leq 0.22$; fruity intensity greater than 0 and no sensory defect perceived) [53].

Regarding the quality and other chemical parameters evaluated (Table 1), the results showed that the olive cultivar had a significant influence on the mean values of all studied parameters ( $P$ value $<0.0001$, one-way ANOVA). In general, cv. Santulhana olive oils showed the highest primary and secondary oxidation indices, and cv. Verdeal Transmontana olive oils had the lowest ones, thus having a slight superior quality level. Table 1 also shows that the oils' OS greatly depended on the cultivar ( $P$ value $<0.0001$, for one-way ANOVA), decreasing the order cv's values as: cv. Verdeal Transmontana $>$ cv. Cobrançosa =cv. Santulhana $>c v$. Madural. This fact can be tentatively attributed to the higher oxidation degradation of monovarietal oils from the latter cultivar, which could be partially related to the lower TPC determined for cv. Madural. However, it should be noticed that oils' oxidation status do not only depend on the TPC level but also with the monounsaturated fatty acids content, mainly oleic acid. However, for the studied monovarietal oils, no direct correlation could be found between OS and TPC.

Concerning the sensory profile, the panelists identified 8 olfactory sensations and 11 gustatory sensations (Table 2), being also assessed the olfactory or gustatory harmony and overall complexity and persistence. The panelists perceived no sensory defect. The olive cultivar had a significant effect ( $P$ value $<0.0001$, one-way ANOVA) on the intensities of the majority of the olfactory and gustatory sensations, including fruitness (green or ripe), basic tastes (sweet, bitter and pungent) and both fruity (apple, banana, dry fruits and tomato) and herbaceous (cabbage, grass and tomato leaves) attributes. Table 2 shows that cv. Santulhana oils were the only fruity greenly oil type among those evaluated, possessing a significantly different sensory profile, being the cultivar for which a significant number of different positive attributes could be perceived. For example, herbaceous sensations (e.g., cabbage, grass and tomato leaves) were only or primarily detected in cv. Santulhana oils, at considerable intensities (with mean intensities ranging from 4.6
Table 1 Mean values ( \pm standard deviation) of free acidity, peroxide value, extinction coefficients, oxidative stability and total phenols contents of monovarietal olive oils from four Portuguese cultivars (cvs. Cobrançosa, Madural, Santulhana and Verdeal Transmontana) (for each oil, $n=6$ bottles $\times 2$ analysis)

\begin{tabular}{lccccc}
\hline Monovarietal olive oils & & & & \\
\hline Parameters $^{1}$ & cv. Cobrançosa & cv. Madural & cv. Santulhana & $\begin{array}{l}\text { cv. Verdeal } \\
\text { transmontana }\end{array}$ & $P$ values $^{2}$ \\
\hline Quality parameters & & & & & \\
FA (g oleic acid/100 g) & $0.24 \pm 0.02^{\mathrm{b}}$ & $0.23 \pm 0.03^{\mathrm{b}}$ & $0.20 \pm 0.03^{\mathrm{b}}$ & $0.35 \pm 0.05^{\mathrm{a}}$ & $<0.0001$ \\
PV (mEq O $/ 2 / \mathrm{kg}$ oil) & $3.88 \pm 0.41^{\mathrm{c}}$ & $4.98 \pm 0.70^{\mathrm{b}}$ & $7.07 \pm 0.83^{\mathrm{a}}$ & $3.32 \pm 0.01^{\mathrm{c}}$ & $<0.0001$ \\
$K_{232}$ & $1.90 \pm 0.17^{\mathrm{b}}$ & $2.01 \pm 0.14^{\mathrm{b}}$ & $2.20 \pm 0.04^{\mathrm{a}}$ & $1.58 \pm 0.10^{\mathrm{c}}$ & $<0.0001$ \\
$K_{268}$ & $0.15 \pm 0.01^{\mathrm{b}}$ & $0.17 \pm 0.02^{\mathrm{a}}$ & $0.18 \pm 0.03^{\mathrm{a}}$ & $0.13 \pm 0.02^{\mathrm{b}}$ & $<0.0001$ \\
Other parameters & & & & & \\
OS $(h)$ & $9.2 \pm 0.6^{\mathrm{b}}$ & $4.8 \pm 0.3^{\mathrm{c}}$ & $9.2 \pm 1.0^{\mathrm{b}}$ & $16.9 \pm 1.0^{\mathrm{a}}$ & $<0.0001$ \\
TPC $(\mathrm{mg} \mathrm{GAE} / \mathrm{kg}$ oil $)$ & $204 \pm 30^{\mathrm{a}}$ & $106 \pm 12^{\mathrm{b}}$ & $177 \pm 33^{\mathrm{a}}$ & $123 \pm 21^{\mathrm{b}}$ & $<0.0001$ \\
\hline
\end{tabular}

${ }^{1} F A$ free acidity, $P V$ peroxide value, $K_{232}$ and $K_{268}$ UV-Vis extinction coefficients at 232 and $268 \mathrm{~nm}$, respectively; $O S$ oxidative stability, $T P C$ total phenols content

${ }^{2} P$ values for the one-way ANOVA. Different letters in the same row show statistically differences from the given mean $(p<0.05)$ 
Table 2 Intensities of olfactory, gustatory and global sensations (mean \pm standard deviation, for each cultivar, $n=6$ olive oil bottles $\times 2$ samples $\times 8$ panelists) perceived by the trained sensory panelists

\begin{tabular}{|c|c|c|c|c|c|c|}
\hline \multirow[t]{2}{*}{ Perceived sensory attribut } & & \multicolumn{4}{|c|}{ Monovarietal olive oils } & \multirow[t]{2}{*}{$P$ values ${ }^{1}$} \\
\hline & & cv. Cobrançosa & cv. Madural & cv. Santulhana & $\begin{array}{l}\text { cv. Verdeal trans- } \\
\text { montana }\end{array}$ & \\
\hline \multicolumn{7}{|l|}{ Olfactory sensations } \\
\hline \multirow[t]{2}{*}{ Fruity } & Greenly & $0.0 \pm 0.0^{\mathrm{b}}$ & $0.0 \pm 0.0^{\mathrm{b}}$ & $5.9 \pm 0.6^{\mathrm{a}}$ & $0.0 \pm 0.0^{\mathrm{b}}$ & $<0.0001$ \\
\hline & Ripely & $6.2 \pm 0.5^{\mathrm{a}}$ & $5.1 \pm 0.8^{\mathrm{b}}$ & $0.0 \pm 0.0^{\mathrm{c}}$ & $5.2 \pm 0.9^{\mathrm{b}}$ & $<0.0001$ \\
\hline \multirow[t]{4}{*}{ Fruit sensations } & Apple & $5.8 \pm 0.7^{\mathrm{a}}$ & $4.1 \pm 1.0^{\mathrm{c}}$ & $5.3 \pm 0.5^{\mathrm{a}, \mathrm{b}}$ & $4.5 \pm 1.1^{\mathrm{b}, \mathrm{c}}$ & $<0.0001$ \\
\hline & Banana & $0.0 \pm 0.0^{\mathrm{b}}$ & $3.0 \pm 1.5^{\mathrm{a}}$ & $0.0 \pm 0.0^{\mathrm{b}}$ & $2.6 \pm 2.0^{\mathrm{a}}$ & $<0.0001$ \\
\hline & Dry fruits & $2.5 \pm 0.4^{\mathrm{c}}$ & $3.2 \pm 0.6^{b c}$ & $3.7 \pm 0.6^{\mathrm{ab}}$ & $4.4 \pm 1.2^{\mathrm{a}}$ & $<0.0001$ \\
\hline & Tomato & $3.4 \pm 1.8^{\mathrm{b}}$ & $4.2 \pm 1.1^{\mathrm{ab}}$ & $5.5 \pm 0.9^{\mathrm{a}}$ & $3.6 \pm 1.8^{\mathrm{b}}$ & 0.0052 \\
\hline \multirow[t]{3}{*}{ Herbaceous sensations } & Cabbage & $0.0 \pm 0.0^{\mathrm{b}}$ & $0.0 \pm 0.0^{\mathrm{b}}$ & $5.6 \pm 1.2^{\mathrm{a}}$ & $0.0 \pm 0.0^{\mathrm{b}}$ & $<0.0001$ \\
\hline & Grass & $0.0 \pm 0.0^{\mathrm{c}}$ & $0.8 \pm 0.8^{\mathrm{b}}$ & $4.6 \pm 1.0^{\mathrm{a}}$ & $0.0 \pm 0.0^{\mathrm{c}}$ & $<0.0001$ \\
\hline & Tomato leaves & $0.0 \pm 0.0^{\mathrm{b}}$ & $0.0 \pm 0.0^{\mathrm{b}}$ & $5.7 \pm 0.8^{\mathrm{a}}$ & $0.0 \pm 0.0^{\mathrm{b}}$ & $<0.0001$ \\
\hline Harmony & & $7.2 \pm 0.2^{\mathrm{a}}$ & $7.7 \pm 0.6^{\mathrm{a}}$ & $7.6 \pm 0.3^{\mathrm{a}}$ & $7.4 \pm 0.5^{\mathrm{a}}$ & 0.1160 \\
\hline \multicolumn{7}{|l|}{ Gustatory sensations } \\
\hline \multirow[t]{2}{*}{ Fruity } & Greenly & $0.0 \pm 0.0^{\mathrm{b}}$ & $0.0 \pm 0.0^{\mathrm{b}}$ & $6.2 \pm 0.5^{\mathrm{a}}$ & $0.0 \pm 0.0^{\mathrm{b}}$ & $<0.0001$ \\
\hline & Ripely & $6.2 \pm 0.5^{\mathrm{a}}$ & $3.5 \pm 1.7^{\mathrm{a}}$ & $0.0 \pm 0.0^{\mathrm{c}}$ & $6.2 \pm 0.6^{\mathrm{a}}$ & $<0.0001$ \\
\hline \multirow[t]{3}{*}{ Basic tastes } & Bitter & $2.4 \pm 0.5^{\mathrm{bc}}$ & $3.1 \pm 0.8^{\mathrm{b}}$ & $4.6 \pm 0.6^{\mathrm{a}}$ & $2.2 \pm 0.6^{\mathrm{c}}$ & $<0.0001$ \\
\hline & Pungent & $3.6 \pm 0.7^{b}$ & $3.7 \pm 0.7^{\mathrm{b}}$ & $5.7 \pm 0.8^{\mathrm{a}}$ & $3.1 \pm 0.6^{\mathrm{b}}$ & $<0.0001$ \\
\hline & Sweet & $7.2 \pm 0.6^{\mathrm{a}}$ & $6.4 \pm 0.4^{\mathrm{b}}$ & $2.2 \pm 0.6^{\mathrm{c}}$ & $6.9 \pm 0.3^{\mathrm{a}}$ & $<0.0001$ \\
\hline \multirow[t]{4}{*}{ Fruit sensations } & Apple & $4.1 \pm 0.5^{\mathrm{b}}$ & $4.2 \pm 1.4^{\mathrm{ab}}$ & $5.0 \pm 0.9^{\mathrm{ab}}$ & $5.2 \pm 0.7^{\mathrm{a}}$ & 0.0099 \\
\hline & Banana & $0.0 \pm 0.0^{\mathrm{c}}$ & $2.8 \pm 2.3^{\mathrm{b}}$ & $0.0 \pm 0.0^{\mathrm{c}}$ & $4.7 \pm 0.6^{\mathrm{a}}$ & $<0.0001$ \\
\hline & Dry fruits & $3.8 \pm 0.7^{\mathrm{a}}$ & $3.0 \pm 0.8^{\mathrm{b}}$ & $3.9 \pm 0.6^{\mathrm{a}}$ & $3.8 \pm 0.6^{\mathrm{a}}$ & 0.0076 \\
\hline & Tomato & $1.2 \pm 1.8^{\mathrm{c}}$ & $3.9 \pm 0.9^{\mathrm{b}}$ & $5.6 \pm 0.7^{\mathrm{a}}$ & $2.2 \pm 1.6^{\mathrm{c}}$ & $<0.0001$ \\
\hline \multirow[t]{3}{*}{ Herbaceous sensations } & Cabbage & $0.0 \pm 0.0^{\mathrm{b}}$ & $0.0 \pm 0.0^{\mathrm{b}}$ & $5.4 \pm 1.6^{\mathrm{a}}$ & $0.0 \pm 0.0^{\mathrm{b}}$ & $<0.0001$ \\
\hline & Grass & $0.0 \pm 0.0^{\mathrm{c}}$ & $1.4 \pm 1.1^{\mathrm{b}}$ & $5.2 \pm 0.9^{\mathrm{a}}$ & $0.0 \pm 0.0^{\mathrm{c}}$ & $<0.0001$ \\
\hline & Tomato leaves & $0.0 \pm 0.0^{\mathrm{b}}$ & $0.0 \pm 0.0^{\mathrm{b}}$ & $5.2 \pm 0.9^{\mathrm{a}}$ & $0.0 \pm 0.0^{\mathrm{b}}$ & $<0.0001$ \\
\hline Harmony & & $6.6 \pm 0.5^{\mathrm{b}}$ & $7.6 \pm 0.6^{\mathrm{a}}$ & $7.4 \pm 0.2^{\mathrm{a}}$ & $7.1 \pm 0.6^{\mathrm{ab}}$ & $<0.0001$ \\
\hline \multicolumn{7}{|l|}{ Global sensations } \\
\hline \multicolumn{2}{|l|}{ Complexity } & $6.0 \pm 0.3^{\mathrm{ab}}$ & $6.6 \pm 0.7^{\mathrm{a}}$ & $6.4 \pm 0.5^{\mathrm{ab}}$ & $5.8 \pm 0.7^{\mathrm{b}}$ & 0.0092 \\
\hline \multicolumn{2}{|l|}{ Persistence } & $7.0 \pm 0.3^{\mathrm{a}}$ & $7.1 \pm 0.4^{\mathrm{a}}$ & $7.4 \pm 0.4^{\mathrm{a}}$ & $7.2 \pm 0.4^{\mathrm{a}}$ & 0.0642 \\
\hline
\end{tabular}

${ }^{1} P$ values for the one-way ANOVA. Different letters in the same row show statistically differences from the given mean $(p<0.05)$

to 5.7). Besides, in general, cv. Santulhana oils showed the highest intensities for most of the perceived positive olfactory and gustatory attributes (except for banana and sweet sensations). Consequently, they had the highest complexity and persistence values. The other three monovarietal oils were classified as fruity ripely oil type, being the cultivar effect highly dependent on the sensory attribute. Lastly, it should be noticed that several of the perceived attributes of the four studied monovarietal olive oils are in line with those previously reported for Portuguese monovarietal oils (e.g., apple, banana, cabbage, dry fruits, grass, tomato and/ or tomato leaves sensations), namely of cvs. Cobrançosa, Madural and Verdeal Transmontana [39, 43, 54].

The observed cultivar significant effect on the studied physicochemical and sensory parameters was further evaluated based on an unsupervised classification approach. From the PCA, it was found that the FA, PV, $K_{232}, K_{268}$, TPC and OS allowed the unsupervised differentiation of the studied monovarietal oils according to the olive cultivar recognition, explaining the first four of the six PCs more than $94 \%$ of the data variability (59.1, 16.9, 10.2 and 8.0\%, respectively). This satisfactory differentiation can be visualized in Fig. 1A (2D-PCA plot). The unsupervised classification pointed out that TPC mainly contributed to the differentiation of cv. Cobrançosa oils; FA and OS to the differentiation of cv. Verdeal Transmontana oils and the primary and secondary oxidation-related parameters allowed the differentiation of cv. Santulhana oils. On the other hand, the sensory profiles allowed a less satisfactory unsupervised differentiation of the studied olive oils (Fig. 1B). In fact, the PCA results (the first four of the 22 PCs only explained $81 \%$ of the data variability, namely, 54.7, 13.3, 7.2 and $6.3 \%$, respectively) 
(A)

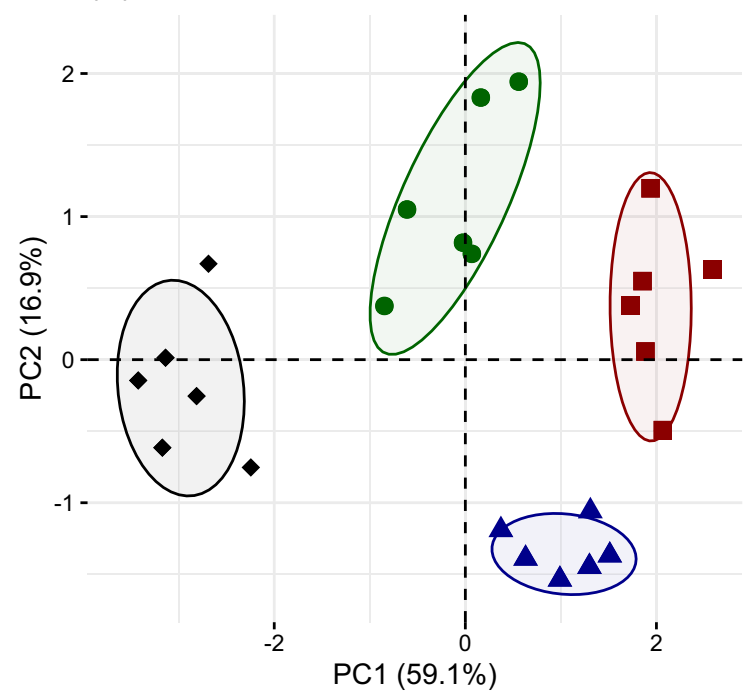

Fig. 1 Monovarietal olive oils unsupervised classification (2D-PCA plot) according to the four studied olive cultivars ( $\mathrm{cv}$. Cobrançosa, $\boldsymbol{\Delta}$ cv. Madural, $\mathbf{c}$ cv. Santulhana, and $\bullet \mathrm{cv}$. Verdeal Transmontana) based on: A six physicochemical parameters ( $F A$ free acidity, $P V$ peroxide values, $K_{232}$ and $K_{268}$ extinction coefficient values at 232 and $268 \mathrm{~nm}$, respectively; $O S$ oxidative stability, and TPC total phenols

evidenced that cv. Santulhana oils were the most easily differentiated, mainly due to attributes like fruity greenly, bitter, pungent, tomato, tomato leaves, grass and cabbage, followed by cv. Cobrançosa oils, being a partial overlap observed for cvs. Madural and Verdeal Transmontana oils. Although physicochemical or sensory data could be used as cultivar-differentiation biomarkers, their implementation would require several analytical techniques (e.g., titration, spectrophotometry and Rancimat) or trained sensory panels, turning out into time-consuming, destructive and/or rather expensive procedures. Therefore, alternative, fast, cost-effective and non-destructive monovarietal cultivar identification tools are needed.

\section{ATR-FTIR spectroscopy}

FTIR analysis was performed using the ATR technique, a straightforward technique where the olive oil sample is directly placed onto the ATR crystal without any previous pretreatment. The vibration bands of the FTIR spectra (Fig. 2) recorded for the cvs. Cobrançosa, Madural, Santulhana, and Verdeal Transmontana monovarietal EVOO were in line with those reported in the literature for olive oils from different cultivars, geographical origins, quality grades, analyzed in fresh or after storage [27, 28, 37, 38], in particular with those described by Machado et al. [36] for cv. Cobrançosa oils produced in the South region of Portugal (Alentejo region). Typical olive oil's absorption
(B)

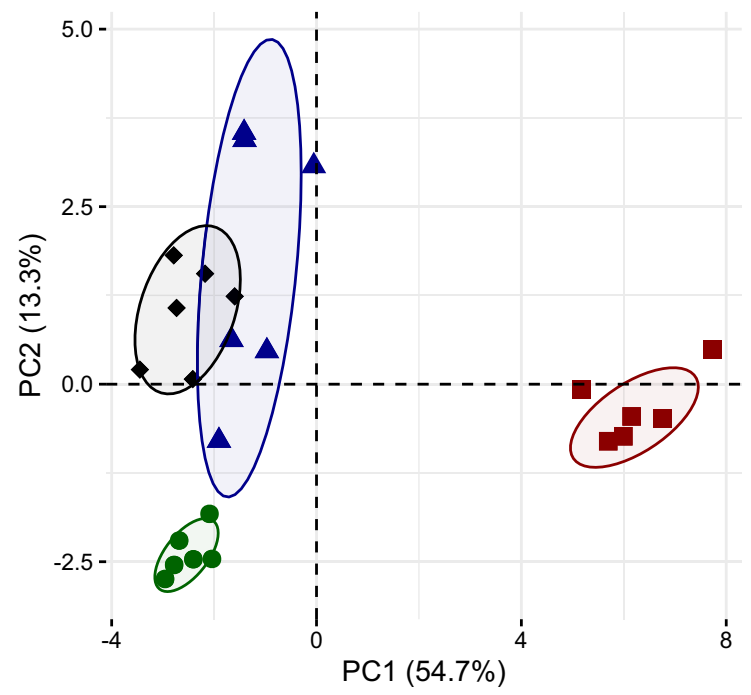

content); and $\mathbf{B}$ intensities of 8 olfactory and 11 gustatory sensations (fruity green or ripe, apple, banana, dry fruits, tomato, cabbage, grass, tomato leaves, sweet, bitter and pungent) perceived by the sensory panel as well as harmony, complexity and persistence attributes (color figure online)

bands were assigned at different wavenumber regions and correlated with vibration modes of the molecular bonds, in agreement with the literature data, widely summarized in recent years [19, 25, 27, 34, 37]. In general, for all studied oils, the raw FTIR spectra showed bands at $721 \mathrm{~cm}^{-1}$, associated with the bending rocking vibration of aliphatic- $-\mathrm{CH}_{2}$ groups; $914 \mathrm{~cm}^{-1}$, related to the bending out of plane vibration of $c i s-\mathrm{HC}=\mathrm{CH}-$ group of disubstituted olefins; region between 1051 and $1161 \mathrm{~cm}^{-1}$, which could be related to the stretching vibrations of saturated $\mathrm{C}-\mathrm{O}$ aliphatic ester groups; $1236 \mathrm{~cm}^{-1}$ related with the stretching vibration of $\mathrm{C}-\mathrm{O}$ acetate groups or of bending vibration of $-\mathrm{CH}_{2} ; 1377 \mathrm{~cm}^{-1}$ linked to the bending vibration of $=\mathrm{CH}$; $1431 \mathrm{~cm}^{-1}$ due to the asymmetrical bending vibration of $-\mathrm{CH}_{3} ; 1464 \mathrm{~cm}^{-1}$ associated with the scissoring bending vibration of aliphatic $-\mathrm{CH}_{2}$ groups; $1653 \mathrm{~cm}^{-1}$ associated to the symmetric stretching vibration of $-\mathrm{CH}_{2} ; 1744 \mathrm{~cm}^{-1}$ due to the stretching vibration of the ester carbonyl groups $(-\mathrm{C}=\mathrm{O})$ of triglycerides; $2853 \mathrm{~cm}^{-1}$ linked to the symmetrical stretching vibration of aliphatic $-\mathrm{CH}_{2}$ and $-\mathrm{CH}_{3}$ groups; $2922 \mathrm{~cm}^{-1}$ associated with the asymmetrical stretching vibration of aliphatic $-\mathrm{CH}_{2}$ groups; $2951 \mathrm{~cm}^{-1}$ related with the asymmetrical stretching vibrations of $-\mathrm{CH}_{3}$ groups; and finally $3007 \mathrm{~cm}^{-1}$ regarding the $\mathrm{CH}$ stretching vibration of cis double bonds $(=\mathrm{C}-\mathrm{H})$.

The visual examination of the ATR-FTIR spectra as well as of the respective 1st and 2nd derivatives (Fig. 2) revealed slight differences between the spectral features 

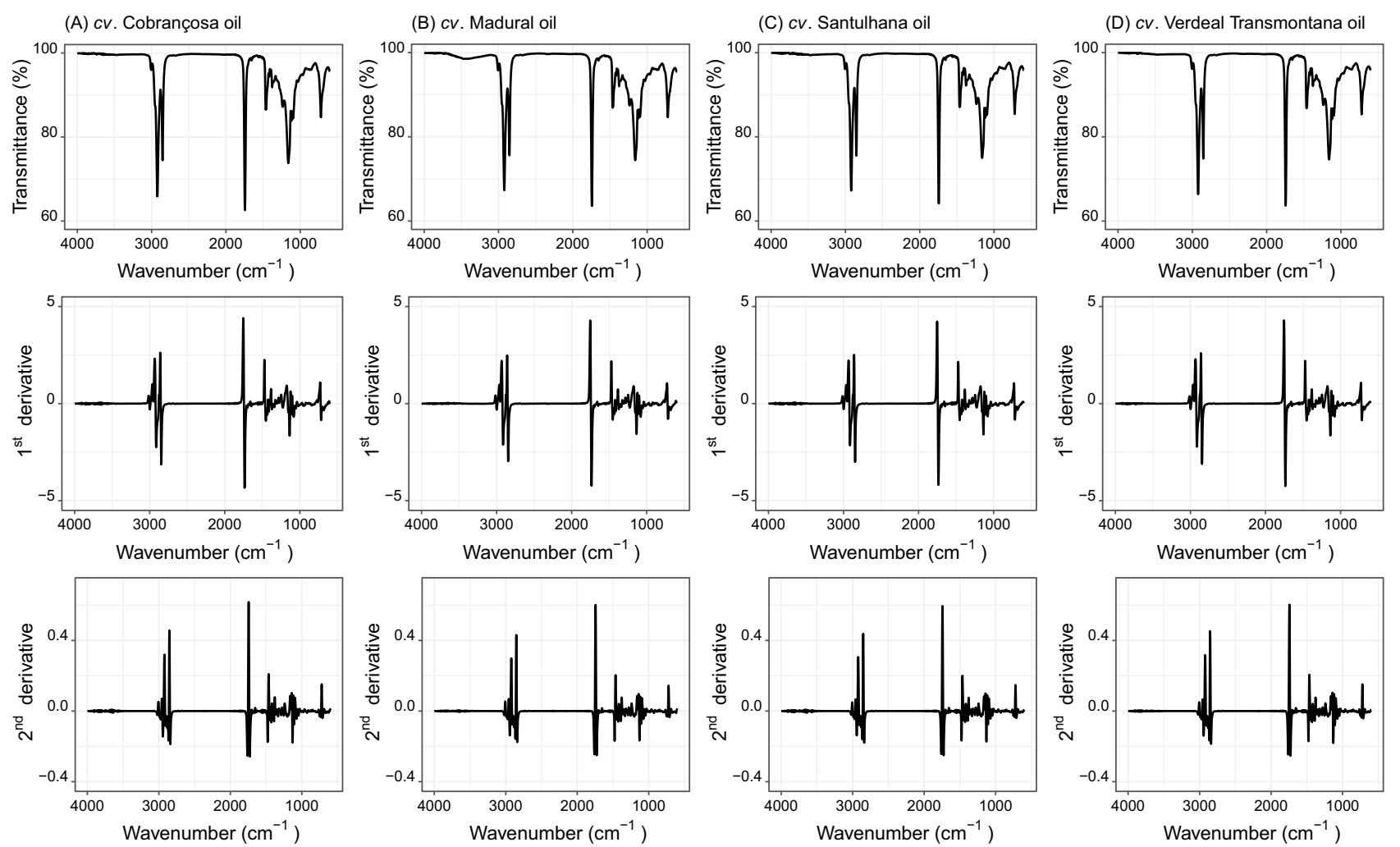

Fig. 2 FTIR spectra (wavenumbers ranging from 4000 to $500 \mathrm{~cm}^{-1}$ ) and respective 1st and 2nd derivatives for monovarietal olive oils of: A cv. Cobrançosa, $\mathbf{B}$ cv. Madural, C cv. Santulhana, and D cv. Verdeal Transmontana (color figure online)

(4000-500 $\left.\mathrm{cm}^{-1}\right)$, more evident for the $3700-3100 \mathrm{~cm}^{-1}$ region, in which, contrary to the other studied oils, the $\mathrm{cv}$. Madural oils showed a large and slight intense band. This band could be associated with the hydroperoxide moieties, which exhibit characteristic absorption bands between 3600 and $3400 \mathrm{~cm}^{-1}$ due to the $-\mathrm{O}-\mathrm{O}-\mathrm{H}$ stretching vibrations, depending on the polarity's peak intensity and the extent of hydrogen interactions [12]. This observed enhancement in the $-\mathrm{OH}$ stretching region of the spectrum (in the $3200-3600 \mathrm{~cm}^{-1}$ ) may be related to a possible higher oxidation level of cv. Madural oils, which is in line with the lower TPC and OS values, compared to the other studied monovarietal oils, as previously discussed for thermoxidized virgin olive oils [55]. The other minor differences observed among the FTIR spectra, according to the cultivar, may be tentatively attributed to the known differences in the chemical composition of the studied monovarietal olive oils, namely in which concerns their volatiles, fatty acids and phenolic profiles [56-59].

Finally, from Fig. 2, two noise regions were identified based on the recorded ATR-FTIR spectra, namely from 2800 to $2000 \mathrm{~cm}^{-1}$ and $4000-3700 \mathrm{~cm}^{-1}$. Thus, to minimize the noise effect on the analysis, these two wavenumber regions were not considered for the multivariate statistical analysis. To evaluate the possibility of using the FTIR spectra and the 1st and 2nd derivatives data to differentiate the monovarietal oils under analysis, according to the four olive cultivars, a PCA was carried out as a first approach using the data recorded between 2000 and $500 \mathrm{~cm}^{-1}$ and $3700-2800 \mathrm{~cm}^{-1}$. Three unsupervised classification models were established based on the raw, 1 st derivaive and 2 nd derivative data, comprising all of them 23 PCs, allowing the first three PCs to explain 95.1, 75.4, and 59.6\% of the data variability. The 3D-PCA plots (Fig. 3) clearly showed that the 1st and 2nd derivatives of the recorded FTIR spectra (Figs. 3B , C) enabled a better unsupervised classification of the four monovarietal oils, compared with the raw spectrabased procedure (Figs. 3A). Morevoer, the analysis based on the 2 nd derivative data allowed a full differentiation of all monovarietal oils, while that based on the 1 st derivative only provided a clear split of cvs. Madural and Santulhana oils. The easier differentiation of cv. Madural oils (achieved using both raw and derivative data) may be tentatively attributed, as previously discussed, to the oils' FTIR spectra main differences observed in the $3600-3100 \mathrm{~cm}^{-1}$ region. The satisfactory classification performance is in-line with the literature, which showed that FTIR-PCA approaches could be successfully used to recognize the cultivar of Turkish monovarietal olive oils [27, 32, 33] or Portuguese and Spanish monovarietal olive oils [35]. 
(A) Raw data (Transmittance, \%)

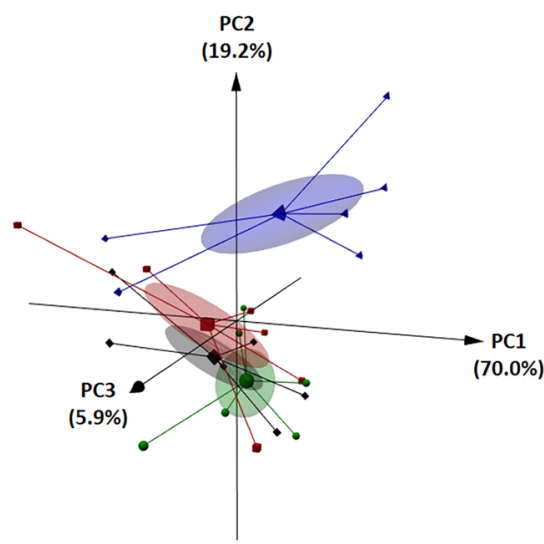

(B) $1^{\text {st }}$ derivative

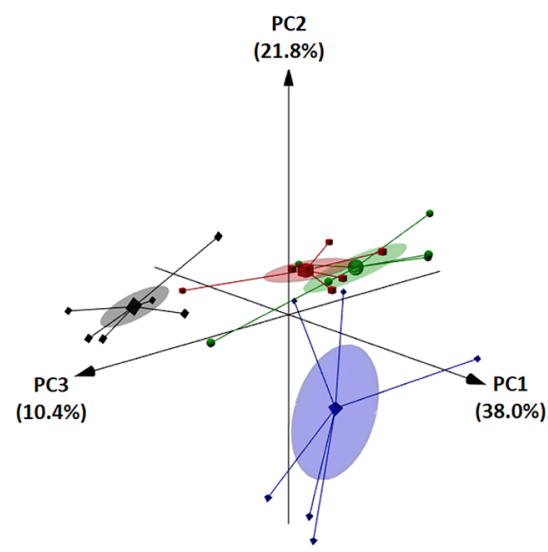

(C) $2^{\text {nd }}$ derivative

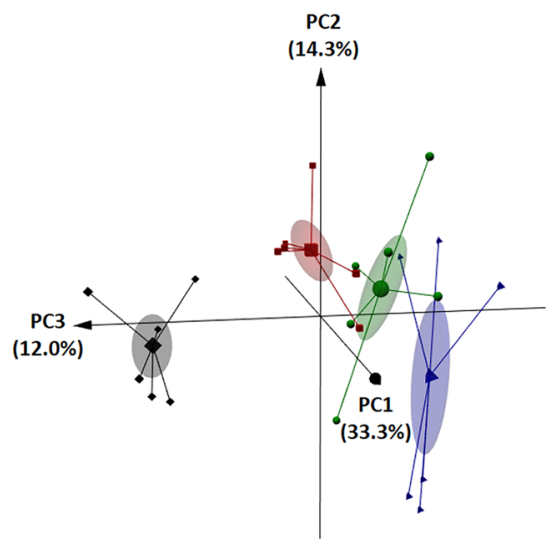

Fig. 3 Monovarietal olive oils unsupervised classification (3D-PCA plot) according to the four studied olive cultivars ( cv. Cobrançosa, $\Delta$ cv. Madural, $\mathbf{c v}$. Santulhana, and $\downarrow$ cv. Verdeal Transmontana) based on the recorded: A FTIR spectrum raw data (transmittance, $\%$; wavenumbers selected regions: $3700-2800 \mathrm{~cm}^{-1}$ and 2000

To further evaluate the potential use of FTIR spectroscopy as a fast and non-destructive olive oil cultivar-recognition tool, LDA-SA was implemented, using the FTIR raw experimental data and both 1 st and 2 nd derivative values. A LDA-SA-FTIR raw data model, for which the two first DFs explained $99.98 \%$ of the data variability, was established based on the transmittance values (\%) from at five non-redundant wavenumbers $(1055,1092,1117,1292$, and $1311 \mathrm{~cm}^{-1}$ ), selected using the SA algorithm as those with the most discrimination power among those belonging to the non-noise regions of the spectra $\left(2000-600 \mathrm{~cm}^{-1}\right.$ and $3700-2800 \mathrm{~cm}^{-1}$, based on Fig. 2). However, data normal distribution was only verified for two of the five selected wavenumbers, namely 1292 and $1311 \mathrm{~cm}^{-1}(0.0692 \leq P$ values $\leq 0.1466$, for the Lilliefors-Kolmogorov-Smirnov normality test). On the other hand, for the selected variables and according to the Box's $M$ test, the homogeneity of variance-covariance matrices was verified $(P$ value $=0.2091)$. Although the variables showed a high correlation (greater or equal to 0.97 ), the selected variables had a collinearity lower than the tolerance of the LDA. It should be highlighted that LDA is fairly robust to moderate violations of these assumptions [50, 51] and so, the established model can still be applied. The selected wavenumbers may be tentatively related with the bending or stretching vibrations of aliphatic saturated $\mathrm{C}-\mathrm{O}$ aliphatic ester groups, $\mathrm{C}-\mathrm{O}$ acetate groups, $\mathrm{O}-\mathrm{H}$ groups, $-\mathrm{CH}_{2}$ groups, or $=\mathrm{CH}$ groups. The multivariate model allowed the correct classification of all samples for the original grouped data (training; Fig. 4A) as well as for LOO-CV, and of $99 \pm 7 \%$ for the repeated K-fold-CV. For this latter $\mathrm{CV}$ variant, the misclassifications were observed between cvs. Cobrançosa and Madural oils, in two of the
$500 \mathrm{~cm}^{-1}$ ), B 1st derivative of the FTIR spectrum data (wavenumbers selected regions: $3700-2800 \mathrm{~cm}^{-1}$ and $2000-500 \mathrm{~cm}^{-1}$ ), and $\mathbf{C}$ 2nd derivative of the FTIR spectrum data (wavenumbers selected regions: $3700-2800 \mathrm{~cm}^{-1}$ and $2000-500 \mathrm{~cm}^{-1}$ ) (color figure online)

40 random repeated resampling. If the 1 st derivative dataset was used, a LDA-SA-1 st derivative model could be established, based on four selected wavenumbers (1105, 2810, 3061, and $3352 \mathrm{~cm}^{-1}$ ), which two first DFs explained $99.99 \%$ of the data variability. For the first three selected wavenumbers, data followed a normal $(0.3365 \leq P$ values $\leq 0.6680$, for the Lilliefors-Kolmogorov-Smirnov normality test). According to the Box's $M$ test, the homogeneity of variance-covariance matrices was verified for the four wavenumbers $(P$ value $=0.6026)$. Although the variables showed a high correlation (greater or equal to 0.97 ), the selected variables had a collinearity lower than the tolerance of the LDA. Moreover, the four selected wavenumbers showed low correlation values (ranging from 0.18 to 0.51 in absolute values), pointing out that the variables showed a low collinearity. Overall, the LDA-SA-1 st derivative model better fulfilled the main assumptions of the LDA compared to the LDA-SA-FTIR raw data model. The selected wavenumbers could be tentatively associated with the stretching vibration of aliphatic $\mathrm{C}-\mathrm{O}$ ester groups, the symmetrical stretching vibration of aliphatic- $-\mathrm{CH}_{2}$ and $-\mathrm{CH}_{3}$ groups or to the $-\mathrm{O}-\mathrm{O}-\mathrm{H}$ stretching vibrations. The model also allowed to correctly classify all monovarietal olive oils (sensitivity and specificity of $100 \%$ ) according to the olive cultivar for the training (Fig. 4B) as well as for LOO-CV, and of $99 \pm 5 \%$ for the repeated K-fold-CV. Similarly to the raw data-based model, misclassifications between cvs. Cobrançosa and Madural oils were detected, in 3 of the 40 random repeated resampling. Finally, a LDA-SA-2nd derivative model was also established based on the data derived from only three wavenumbers $\left(1111,1209\right.$ and $\left.2829 \mathrm{~cm}^{-1}\right)$, explaining the two first DFs $99.98 \%$ of the data variability. 
(A)

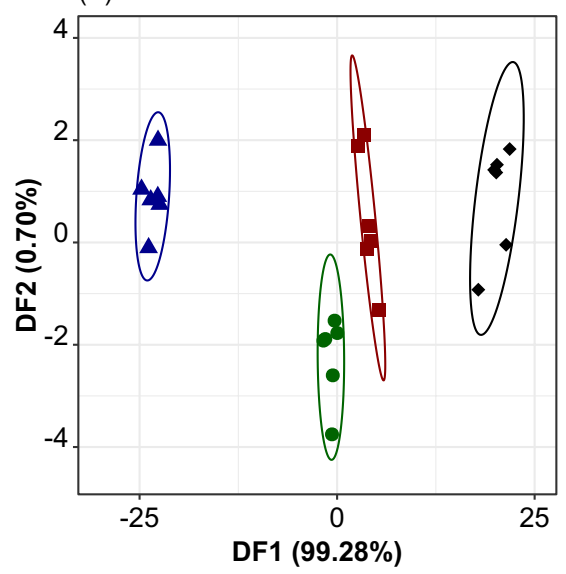

(B)

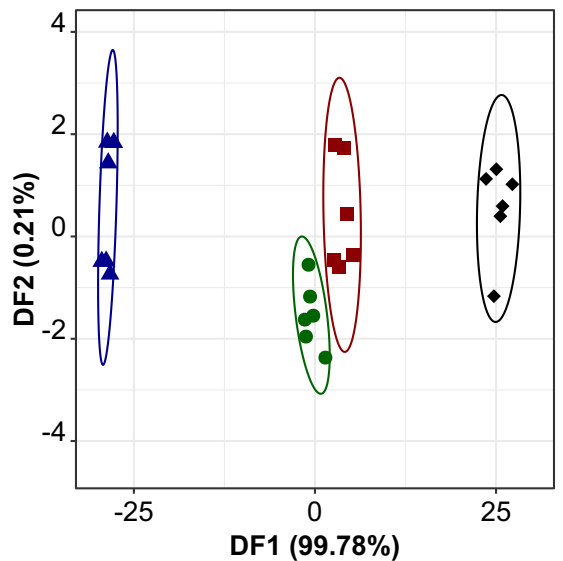

(C)

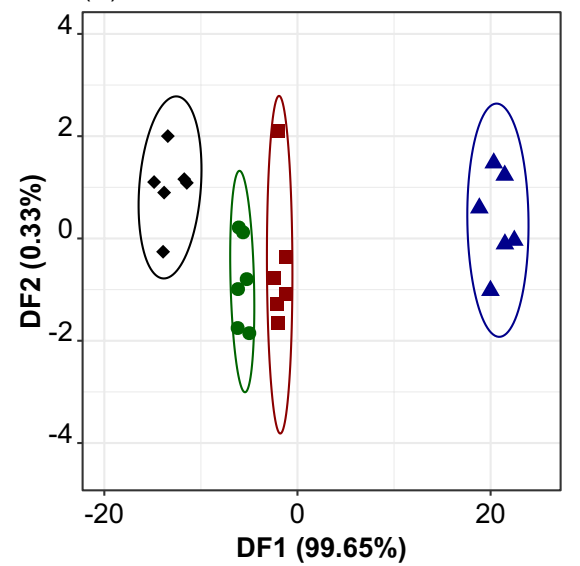

Fig. 4 Monovarietal olive oils supervised discrimination (2D-LDASA plot) according to the four studied olive cultivars ( cv. Cobrançosa, $\boldsymbol{\Delta}$ cv. Madural, $\mathbf{c v}$. Santulhana, and $\bullet \mathrm{cv}$. Verdeal Transmontana) based on: A LDA-SA-FTIR raw data model based on the transmittance (\%) values recorded at five wavenumbers $(1055,1092$, 1117,1292 , and $1311 \mathrm{~cm}^{-1}$ ) selected by the SA algorithm, B LDA-

The selected wavenumbers were tentatively related with the stretching vibrations of saturated $\mathrm{C}-\mathrm{O}$ aliphatic ester groups, to the bending vibration of $-\mathrm{CH}_{2}$ and to the symmetrical stretching vibration of aliphatic $-\mathrm{CH}_{2}$ and $-\mathrm{CH}_{3}$ groups. The model correctly classified the monovarietal olive oils (sensitivity and specificity of $100 \%$ ) according to the olive cultivar for the original grouped data (Fig. 4C) as well as for LOO-CV, and showed an average sensitivity of $99 \pm 2 \%$ for the repeated K-fold-CV. Similarly to the other models, misclassifications were observed between cvs. Cobrançosa and Madural oils, in only one of the 40 random resampling. However, it should be remarked that even if the homogeneity of variance-covariance rrequirement was fullfilled ( $P$ value $=0.2793$, for the Box's $M$ test , only the derived data related with the wavenumber of $1111 \mathrm{~cm}^{-1}$ had a normal distribution. Morevover, two of the selected wavenumbers (1209 and $2829 \mathrm{~cm}^{-1}$ ) showedd a high correlation (equal to 0.97$)$.

Although the three approaches were feasible and even considering that the LDA models are robust to moderate violations towards the variables' normal distribution and non-colinearity, it can be inferred that the LDA model based on the 1st derivative data would be the most adequate to be used as a predicitve tool for discriminating the four studied monovarietal oils according to the correct olive cultivar. Also, it shoud be referred that, in general, the predictive discrimination performances of the developed FTIR based models are similar or slightly better than the supervised classifications obtained with FTIR-LDA models previously developed by Concha-Herrera et al. [34] for discriminating seven Spanish monovarietal oils (sensitivities of 74-88\%),
SA-1st derivative model based on the 1st derivative of the transmittance $(\%)$ values recorded at four wavenumbers $(1105,2810,3061$, and $3352 \mathrm{~cm}^{-1}$ ) selected by the SA algorithm, and C LDA-SA-2nd derivative model based on the 2 nd derivative of the transmittance (\%) values recorded at three wavenumbers $\left(1111,1209\right.$ and $2829 \mathrm{~cm}^{-1}$ ) selected by the SA algorithm (color figure online)

by Abdallah et al. [37] for classifying Tunisian monovarietal olive oils (sensitivity of $100 \%$ ) or by Revelou et al. [38] to assess the botanical origin of Greek monovarietal olive oils (sensitivity of $96 \%$ ).

Lastly, it could be stated that the PCA and LDA models developed in this study, using FTIR raw or transformed data, could be used as a practical and accurate tool to discriminate cvs. Cobrançosa, Madural, Santulhana, and Verdeal Transmontana oils allow verifying these Portuguese monovarietal oils' authenticity, which is of major relevance for high demanding consumers of monovarietal olive oil producers.

\section{Conclusions}

The present study evaluated the effect of the olive cultivar on the physicochemical and sensory characteristics of monovarietal olive oils from four different Portuguese cultivars, industrially obtained in similar extractions conditions. The findings confirmed that free acidity, peroxide value, extinction coefficients, total phenols content and oxidative stability could be used as biomarkers to successfully differentiate the four extra-virgin monovarietal olive oils, and to a less extent, the sensory profiles (positive olfactory and gustatory sensations). However, both strategies are time-consuming and invasive approaches. In contrast, Fourier Transform Infrared spectroscopy, coupled with unsupervised and supervised chemometric techniques, and based on raw transmittance spectra or their 1 st or 2 nd derivative, allowed good discrimination of the monovarietal olive oils, enabling to correctly predict the olive cultivar, among the four considered olive 
cultivars (cvs. Cobrançosa, Madural, Santulhana or Verdeal Transmontana). In conclusion, the spectroscopy approach showed to be a promising, reliable, fast and non-destructive olive cultivar-traceability tool, being foreseen its possible practical application, in the near future, ensuring the monovarietal labeling correctness and thus, enhancing the confidence of the demanding olive oil consumers. Nevertheless, to validate and strengthen the predictive performance of the proposed spectroscopy-chemometric procedure, it would be essential to expand the study to include other potential interesting monovarietal olive oils produced in different geographical regions.

Acknowledgements The authors are grateful to the Foundation for Science and Technology (FCT, Portugal) for financial support by national funds FCT/MCTES to CIMO (UIDB/00690/2020) and Project "GreenHealth-Digital strategies in biological assets to improve well-being and promote green health" (Norte-01-0145-FEDER-000042) funded by the European Regional Development Fund under the scope of Norte2020-Programa Operacional Regional do Norte. Nuno Rodrigues and Isabel P. Fernandes thank to National funding by FCTFoundation for Science and Technology, P.I., through the institutional scientific employment program contract.

Authors contribution Conceptualization: MFB, JAP, and AMP. Methodology: NR, MFB, JAP, and AMP. Data analysis and interpretation: MFB, JAP, and AMP. Investigation: SL, IPF, and NR. Data Curation: SL and NR. Writing and editing: MFB, JAP, and AMP. Revision and final approval: all the authors.

\section{Declarations}

Conflict of interest The authors declare that they have no conflict of interest.

Compliance with ethics requirements This article does not contain any studies with human participants or animals, as ruled by the Directive 2010/63/EU, performed by any of the authors.

\section{References}

1. Sacchi R, Della Medaglia D, Paduano A, Caporaso N, Genovese A (2017) Characterisation of lemon-flavoured olive oils. LWT-Food Sci Technol 79:326-332. https://doi.org/10.1016/j.lwt.2017.01. 025

2. Agrimonti C, Marmiroli N (2019) Food genomics for the characterization of PDO and PGI virgin olive oils. Eur J Lipid Sci Tech 121:1800132. https://doi.org/10.1002/ejlt.201800132

3. Messai H, Farman M, Sarraj-Laabidi A, Hammami-Semmar A, Semmar N (2016) Chemometrics methods for specificity, authenticity and traceability analysis of olive oils: principles, classifications and applications. Foods 5:77. https://doi.org/10.3390/foods 5040077

4. Cecchi L, Migliorini M, Mulinacci N (2021) Virgin olive oil volatile compounds: Composition, sensory characteristics, analytical approaches, quality control, and authentication. J Agric Food Chem 69:2013-2040. https://doi.org/10.1021/acs.jafc.0c07744
5. Ou G, Hu R, Zhang L, Li P, Luo X, Zhang Z (2015) Advanced detection methods for traceability of origin and authenticity of olive oils. Anal Methods 7:5731-5739. https://doi.org/10.1039/ c5ay00048c

6. Skládal P (2020) Smart bioelectronic tongues for food and drinks control. Trends Analyt Chem 127:115887. https://doi. org/10.1016/j.trac.2020.115887

7. Zaroual H, Chénè C, El Hadrami EM, Karoui R (2021) Application of new emerging techniques in combination with classical methods for the determination of the quality and authenticity of olive oil: a review. Crit Rev Food Sci Nutr. https://doi.org/ 10.1080/10408398.2021.1876624

8. Lioupi A, Nenadis N, Theodoridis G (2020) Virgin olive oil metabolomics: a review. J Chromatogr B Analyt Technol Biomed Life Sci 1150:122161. https://doi.org/10.1016/j.jchro mb.2020.122161

9. Pereira AG, Otero P, Fraga-Corral M, Garcia-Oliveira P, Carpena M, Prieto MA, Simal-Gandara J (2021) State-of-theart of analytical techniques to determine food fraud in olive oils. Foods 10:484. https://doi.org/10.3390/foods 10030484

10. Valand R, Tanna S, Lawson G, Bengtström L (2020) A review of Fourier transform infrared (FTIR) spectroscopy used in food adulteration and authenticity investigations. Food Addit Contam Part A Chem Anal Control Expo Risk Assess 37:19-38. https:// doi.org/10.1080/19440049.2019.1675909

11. Sikorska E, Khmelinskii I, Sikorski M (2014) Chapter 7 vibrational and electronic spectroscopy and chemometrics in analysis of edible oils. In: Vieira M, Khmelinskii I, Cruz RMS (eds) Methods in food analysis, 1 st edn. CRC Press, Boca Raton, pp 201-234. https://doi.org/10.1201/b16964

12. Bendini A, Cerretani L, Di Virgilio F, Belloni P, Bonoli-Carbognin M, Lercker G (2007) Preliminary evaluation of the application of the ftir spectroscopy to control the geographic origin and quality of virgin olive oils. J Food Qual 30:424-437. https://doi.org/10.1111/j.1745-4557.2007.00132.x

13. Cerretani L, Giuliani A, Maggio RM, Bendini A, Toschi TG, Cichelli A (2010) Rapid FTIR determination of water, phenolics and antioxidant activity of olive oil. Eur J Lipid Sci Tech 112:1150-1157. https://doi.org/10.1002/ejlt.201000356

14. Filoda PF, Fetter LF, Fornasier F, Schneider RCS, Helfer GA, Tischer B, Teichmann A, da Costa AB (2019) Fast methodology for identification of olive oil adulterated with a mix of different vegetable oils. Food Anal Methods 12:293-304. https://doi.org/ 10.1007/s12161-018-1360-5

15. Lobo-Prieto A, Tena N, Aparicio-Ruiz R, Morales MT, GarcíaGonzález DL (2020) Tracking sensory characteristics of virgin olive oils during storage: interpretation of their changes from a multiparametric perspective. Molecules 25:1686. https://doi. org/10.3390/molecules25071686

16. Machado M, Machado N, Gouvinhas I, Cunha M, de Almeida JMMM, Barros AIRNA (2015) Quantification of chemical characteristics of olive fruit and oil of cv cobrançosa in two ripening stages using MIR spectroscopy and chemometrics. Food Anal Methods 8:1490-1498. https://doi.org/10.1007/ s12161-014-0017-2

17. Tarhan İ (2020) A comparative study of ATR-FTIR, UV-visible and fluorescence spectroscopy combined with chemometrics for quantification of squalene in extra virgin olive oils. Spectrochim Acta A Mol Biomol Spectrosc 241:118714. https://doi.org/10. 1016/j.saa.2020.118714

18. Tarhan İ, Ismail AA, Kara H (2017) Quantitative determination of free fatty acids in extra virgin olive oils by multivariate methods and fourier transform infrared spectroscopy considering different absorption modes. Int J Food Prop 20:S790-S797. https://doi.org/10.1080/10942912.2017.1312437 
19. Uncu O, Ozen B, Tokatli F (2019) Use of FTIR and UV-visible spectroscopy in determination of chemical characteristics of olive oils. Talanta 201:65-73. https://doi.org/10.1016/j.talanta. 2019.03.116

20. Jiménez-Carvelo AM, Osorio MT, Koidis A, González-Casado A, Cuadros-Rodríguez L (2017) Chemometric classification and quantification of olive oil in blends with any edible vegetable oils using FTIR-ATR and Raman spectroscopy. LWT-Food Sci Technol 86:174-184. https://doi.org/10.1016/j.lwt.2017.07.050

21. Jović O, Smolić T, Primožič I, Hrenar T (2016) Spectroscopic and chemometric analysis of binary and ternary edible oil mixtures: qualitative and quantitative study. Anal Chem 88:4516-4524. https://doi.org/10.1021/acs.analchem.6b00505

22. Pan M, Sun S, Zhou Q, Chen J (2018) A simple and portable screening method for adulterated olive oils using the hand-held FTIR spectrometer and chemometrics tools. J Food Sci 83:16051612. https://doi.org/10.1111/1750-3841.14190

23. Rohman A, Che Man YB, Ismail A, Hashim P (2017) FTIR spectroscopy coupled with chemometrics of multivariate calibration and discriminant analysis for authentication of extra virgin olive oil. Int J Food Prop 20:S1173-S1181. https://doi.org/10.1080/ 10942912.2017.1336718

24. Rohman A, Che Man YB, Yusof FM (2014) The use of FTIR spectroscopy and chemometrics for rapid authentication of extra virgin olive oil. J Am Oil Chem Soc 91:207-213. https://doi.org/ 10.1007/s11746-013-2370-5

25. Socaciu C, Fetea F, Ranga F, Bunea A, Dulf F, Socaci S, Pintea A (2020) Attenuated total reflectance-fourier transform infrared spectroscopy (ATR-FTIR) coupled with chemometrics, to control the botanical authenticity and quality of cold-pressed functional oils commercialized in Romania. Appl Sci 10:8695. https://doi. org/10.3390/app10238695

26. Sun X, Lin W, Li X, Shen Q, Luo H (2015) Detection and quantification of extra virgin olive oil adulteration with edible oils by FT-IR spectroscopy and chemometrics. Anal Methods 7:39393945. https://doi.org/10.1039/c5ay00472a

27. Üçüncüoğlu D, Küçük VA (2019) A multivariate data approach for FTIR-ATR monitoring of virgin olive oils: lipid structure during autoxidation. Oilseeds Fats Crops Lipids 26:42. https://doi. org/10.1051/ocl/2019043

28. Uncu O, Ozen B, Tokatli F (2020) Authentication of Turkish olive oils by using detailed pigment profile and spectroscopic techniques. J Sci Food Agric 100:2153-2165. https://doi.org/10. $1002 /$ jsfa. 10239

29. Nenadis N, Tsikouras I, Xenikakis P, Tsimidou MZ (2013) Fourier transform mid-infrared spectroscopy evaluation of early stages of virgin olive oil autoxidation. Eur J Lipid Sci Tech 115:526-534. https://doi.org/10.1002/ejlt.201200317

30. Tena N, Aparicio-Ruiz R, García-González DL (2014) Use of polar and nonpolar fractions as additional information sources for studying thermoxidized virgin olive oils by FTIR. Grasas Aceites 65:e30. https://doi.org/10.3989/gya.121913

31. Hirri A, Bassbasi M, Platikanov S, Tauler R, Oussama A (2016) FTIR spectroscopy and PLS-DA classification and prediction of four commercial grade virgin olive oils from Morocco. Food Anal Methods 9:974-981. https://doi.org/10.1007/s12161-015-0255-y

32. Gurdeniz G, Tokatli F, Ozen B (2007) Differentiation of mixtures of monovarietal olive oils by mid-infrared spectroscopy and chemometrics. Eur J Lipid Sci Tech 109:1194-1202. https://doi. org/10.1002/ejlt.200700087

33. Gurdeniz G, Ozen B, Tokatli F (2008) Classification of Turkish olive oils with respect to cultivar, geographic origin and harvest year, using fatty acid profile and mid-IR spectroscopy. Eur Food Res Tech 227:1275-1281. https://doi.org/10.1007/ s00217-008-0845-7
34. Concha-Herrera V, Lerma-García MJ, Herrero-Martínez JM, Simó-Alfonso EF (2009) Prediction of the genetic variety of extra virgin olive oils produced at La Comunitat Valenciana, Spain, by Fourier Transform Infrared Spectroscopy. J Agric Food Chem 57:9985-9989. https://doi.org/10.1021/jf901730p

35. Gouvinhas I, De Almeida JMMM, Carvalho T, Machado N, Barros AIRNA (2015) Discrimination and characterization of extra virgin olive oils from three cultivars in different maturation stages using Fourier transform infrared spectroscopy in tandem with chemometrics. Food Chem 174:226-232. https://doi.org/10.1016/j. foodchem.2014.11.037

36. Machado M, Machado N, Gouvinhas I, Domínguez-Perles R, AIRNA Barros (2017) FTIR chemometrical approach for clonal assessment: Selection of Olea europaea L. optimal phenotypes from cv. Cobrançosa. J Chemom 31:e2860. https://doi.org/10. 1002/cem. 2860

37. Abdallah M, Vergara-Barberán M, Lerma-García MJ, HerreroMartínez JM, Simó-Alfonso EF, Guerfel M (2016) Cultivar discrimination and prediction of mixtures of Tunisian extra virgin olive oils by FTIR. Eur J Lipid Sci Tech 118:1236-1242. https:// doi.org/10.1002/ejlt.201500041

38. Revelou PK, Pappa C, Kakouri E, Kanakis CD, Papadopoulos GK, Pappas CS, Tarantilis PA (2021) Discrimination of botanical origin of olive oil from selected Greek cultivars by SPME-GC-MS and ATR-FTIR spectroscopy combined with chemometrics. J Sci Food Agric 101:2994-3002. https://doi.org/10.1002/jsfa.10932

39. Rodrigues N, Casal S, Peres AM, Baptista P, Pereira JA (2020) Seeking for sensory differentiated olive oils? The urge to preserve old autochthonous olive cultivars. Food Res Int 128:108759. https://doi.org/10.1016/j.foodres.2019.108759

40. European Union Commission Regulation, Regulation CE 1989/2003 (2003) Amending regulation EEC 2568/91 on the characteristics of olive oil and olive-pomace oil and on the relevant methods of analysis. Off J Eur Com L295:57-58

41. Rodrigues N, Marx ÍMG, Casal S, Dias LG, Veloso ACA, Pereira JA, Peres AM (2019) Application of an electronic tongue as a single-run tool for olive oils' physicochemical and sensory simultaneous assessment. Talanta 197:363-373. https://doi.org/10.1016/j. talanta.2019.01.055

42. Capannesi C, Palchetti I, Mascini M, Parenti A (2000) Electrochemical sensor and biosensor for polyphenols detection in olive oils. Food Chem 71:553-562. https://doi.org/10.1016/S03088146(00)00211-9

43. Marx ÍMG, Rodrigues N, Veloso ACA, Casal S, Pereira JA, Peres AM (2021) Effect of malaxation temperature on the physicochemical and sensory quality of $\mathrm{cv}$. Cobrançosa olive oil and its evaluation using an electronic tongue. LWT-Food Sci Technol 137:110426. https://doi.org/10.1016/j.lwt.2020.110426

44. International Olive Council (2005) Method for the organoleptic assessment of extra virgin olive oil applying to use a designation of origin. Document COI/T.20/Doc. No. 22, 29p, Madrid. https:// www.internationaloliveoil.org/wp-content/uploads/2019/11/COIT.20-Doc.-No-22-2005-Eng-1.pdf

45. Xiaobo Z, Jiewen Z, Povey MJW, Holmes M, Hanpin M (2010) Variables selection methods in near-infrared spectroscopy. Anal Chim Acta 667:14-32. https://doi.org/10.1016/j.aca.2010.03.048

46. Kirkpatrick S, Gelatt CD Jr, Vecchi MP (1983) Optimization by simulated annealing (1983). Science 220:671-680. https://doi.org/ 10.1126/science.220.4598.671

47. Swierenga H, De Groot PJ, De Weijer AP, Derksen MWJ, Buydens LMC (1998) Improvement of PLS model transferability by robust wavelength selection. Chemometr Intell Lab Syst 41:237-248. https://doi.org/10.1016/S0169-7439(98)00055-0

48. Kalivas JH, Roberts N, Sutter JM (1989) Global optimization by simulated annealing with wavelength selection for 
ultraviolet-visible spectrophotometry. Anal Chem 61:2024-2030. https://doi.org/10.1021/ac00193a006

49. Swierenga H, Wülfert F, De Noord OE, De Weijer AP, Smilde AK, Buydens LMC (2000) Development of robust calibration models in near infra-red spectrometric applications. Anal Chim Acta 411:121-135. https://doi.org/10.1016/S0003-2670(00) 00718-2

50. Li T, Zhu S, Ogihara M (2006) Using discriminant analysis for multi-class classification: an experimental investigation. Knowl Inf Syst 10:453-472. https://doi.org/10.1007/s10115-006-0013-y

51. McGarigal K, Cushman S, Susan S (2000) Multivariate statistics for wildlife and ecology research. Springer-Verlag, New York

52. Bishop CM (2006) Pattern recognition and machine learning, 1st edn. Springer, New York

53. CD Regulation (EU) $\mathrm{N}^{\circ} 2015,1830$ of 8th, July 2015 (2015) Amending Regulation (EEC) $\mathrm{N}^{\circ} 2568 / 91$ on the characteristics of olive oil and olive-residue oil and on the relevant methods of analysis. Off J Eur Union L266:9-13

54. Fernandes-Silva AA, Falco V, Correia CM, Villalobos FJ (2013) Sensory analysis and volatile compounds of olive oil (cv. Cobrançosa) from different irrigation regimes. Grasas Aceites 64:59-67. https://doi.org/10.3989/gya.069712

55. Tena N, Aparicio-Ruiz R, García-González DL (2013) Time course analysis of fractionated thermoxidized virgin olive oil by FTIR spectroscopy. J Agric Food Chem 61:3212-3218. https:// doi.org/10.1021/jf305422d
56. Malheiro R, Casal S, Cunha SC, Baptista P, Pereira JA (2015) Olive volatiles from Portuguese cultivars Cobrançosa, Madural and Verdeal Transmontana: role in oviposition preference of Bactrocera oleae (Rossi) (Diptera: Tephritidae). PLoS One 10:e0125070. https://doi.org/10.1371/journal.pone.0125070

57. Matos LC, Cunha SC, Amaral JS, Pereira JA, Andrade PB, Seabra RM, Oliveira BPP (2007) Chemometric characterization of three varietal olive oils (Cvs. Cobrançosa, Madural and Verdeal Transmontana) extracted from olives with different maturation indices. Food Chem 102:406-414. https://doi.org/10.1016/j.foodchem. 2005.12.031

58. Peres F, Martins LL, Mourato M, Vitorino C, Ferreira-Dias S (2016) Bioactive compounds of portuguese virgin olive oils discriminate cultivar and ripening stage. J Am Oil Chem Soc 93:1137-1147. https://doi.org/10.1007/s11746-016-2848-z

59. Rodrigues N, Casal S, Pinho T, Cruz R, Peres AM, Baptista P, Pereira JA (2021) Fatty acid composition from olive oils of Portuguese centenarian trees is highly dependent on olive cultivar and crop year. Foods 10:496. https://doi.org/10.3390/foods10030496

Publisher's Note Springer Nature remains neutral with regard to jurisdictional claims in published maps and institutional affiliations. 